\title{
DOES LAW HAVE A FUNCTION? A COMMENT ON THE TWO-LEVEL THEORY OF DECISION*
}

\author{
RONALD DWORKIN $\dagger$
}

WHAT, in general, is a good reason for decision by a court of law? This is the question of jurisprudence; it has been asked in an amazing number of forms, of which the classic "What is Law?" is only the briefest. I propose to consider, in this Comment, one recent answer to this question - that supplied by Professor Richard Wasserstrom in his book, The Judicial Decision. I do so because Professor Wasserstrom's argument shares with much other recent jurisprudence some dubious and generally unrecognized assumptions about the logic of legal justification. My principal purpose is to expose these assump. tions.

Wasserstrom's book is distinguished from the bulk of the American literature of legal philosophy by its care and clarity. He writes with full control over his organization and so enables us to study his argument with some confidence that we understand what he is trying to prove and why. This is in refreshing contrast to other recent efforts along the same line - much of American jurisprudence has consisted in nothing more rigorous than the translation of homilies into rhetoric, and back again. Wasserstrom's careful articulation of his purposes, and of the assumptions he intends to make, are indispensable aids in identifying and assessing the hidden more powerful assumptions which his argument also involves.

Wasserstrom approaches the question, "What is a good reason for a judicial decision," by attempting to construct the model of an "ideal" decisive procedure. His search for this "ideal" is conducted through a sort of tournament. Three principal candidates are introduced. The first two are the procedures of precedent (it "prescribes that all particular cases are to be decided by an appeal to the relevant, extant legal rule, i.e., to precedent") ${ }^{2}$ and the procedure of equity (it "insists that individual cases be decided by appealing to that which is just or equitable for the particular case").$^{3}$ The third is Wasserstrom's own two-level procedure, modeled on the ethical doctrine of "restricted utilitarinn. ism." It counsels the judge faced with decision to proceed as follows. He must determine which of the rules of law that he might select to give in the situation, considered as a rule and not simply with respect to its present application, best promotes the function of the legal system. (It is assumed that each legal system ought to have such a function.) In making this determination, he must take

*Previously printed, in slightly different form, under the title "Wasserstrom: The Judicial Decision," 75 Ermics 47 (1964) (University of Chicago Press) [Copyright 1964 by the University of Chicago].

†Associate Professor of Law, Yale University.

1. Wasserstron, The Judictar Deciston (1961).

2. Id. at 6 .

3. Id. at 7 . 
into account such factors as the scope and the generality of each proposed rule, and whether, if some extant rule purports to apply, the gain from replacing it with a new rule would survive the disturbance caused by the replacement. Once the proper rule is chosen, he must apply that rule to the facts of the case and so reach his decision, notwithstanding that he might not regard that decision as the most equitable or fairest "between the parties." The two-level procedure is thus unlike the procedure of precedent in that "appeal to a legal rule" while a "necessary condition" is not a "sufficient condition" for a particular decision, and unlike the procedure of equity "in that the justice of a legal rule ... rather than the justice of the particular decision, is the sufficient condition for a particular decision." In the end, the two-level procedure is found superior to either of the others, although itself not free from difficulty.

The procedures of precedent and equity, so described, are acknowledged to be only paradigms of theories. Wasserstrom identifies and challenges several of the variations in which each has actually been advanced by prominent legal philosophers. And so we are treated to a series of skirmishes: Wasserstrom versus Aristotle, Wasserstrom versus Salmond, Wasserstrom versus Pound, and so on. These discussions are rich in pertinent obervations and distinctions, and permit Wasserstrom to show his dialectical skill. Along the way he exposes (perhaps it will not be necessary to do it again) the silly things which have been said about logic in the name of legal philosophy.

The central argument, however, proceeds in terms of the paradigm theories, and on the basis of a series of assumptions and a model legal system. The assumptions and the model are presented as conveniences, limiting and sharpening the focus of the inquiry. Yet once we have accepted them, and accepted the paradigm theories as fair antagonists, we seem drawn into a series of decisions each of which turns out to be Hobson's choice. We are given to choose between judges who invariably follow judicial rules already laid down, for no other reason than that they have been, and judges who stand ready to reject an old rule when they are satisfied that, all things considered (and discounting for the mischief caused by the change itself), abandoning that rule will better serve the function of law. Having made this decision, we are presented with a further choice between judges who legislate entirely ad hoc and $e x$ post facto, without reference to standards carrying even a qualified promise for the future, and judges who legislate by laying down principles of general application which they (at the time at least) intend to follow in like cases. As Wasserstrom reveals, explicitly and implicitly, his assumptions about the process of judicial decision, these are the sets of alternatives we confront; and when we have finished choosing in the only way we can, we find we have accepted the twolevel theory. The concepts that these assumptions permit us cannot be assembled to yield any other plausible decision procedure. It is this poverty of real options presented which causes the smell of straw hanging about the alleged antagonists

4. Ibid. 
he defeats, and which has prompted some of his reviewers to find his conclusions in themselves obvious. ${ }^{5}$

The reader would do well, therefore, to inspect not Wasserstrom's reasoning, but his premises, not the adequacy of his two-level technique for the model legal system he constructs, but the adequacy of that model as a vehicle for understanding our own. For the book is a sort of jurisprudential shell game, and Wasserstrom's most crucial views on the judicial decision turn out to be imbedded in his assumptions. His failure to examine these assumptions leads not to a benign curtailment of his study, but to a situation in which the critical questions of that study are at the outset placed beyond its scope. And the apparent reasonableness of his conclusions signals not the accuracy of these assumptions but only their popularity.

Cardinal among these assumptions is the belief that there is some general goal or function which our legal system ought to serve. This belief is crucial to the two-level procedure: I propose to study it here for that reason, and because similar assumptions have seemed reasonable and important to a great many other legal philosophers.

Most of what Wasserstrom has to say about this critical and complex as" sumption is set out in one paragraph:

A third important assumption relates to the question of what general function or functions a legal system ought to fulfill. Although I endeavor in this inquiry to call into question certain theses of contemporary AngloAmerican jurisprudence, I do not propose to challenge the common view that the legal system ought in some very general sense to perform an essentially utilitarian function. That is, I shall suppose throughout most of this study that a desirable legal system is one that succeeds in giving maximum effect to the needs, desires, interests, and aspirations of the members of the society of which it is a part. Thus, this inquiry is concerned almost exclusively with the relationship between this very general goal and various possible judicial decision procedures. It is, of course, legitimate to call into question the desirability of this goal, and in one chapter I do indicate briefly the direction that such a perusal might take. I do not, however, seek to do more than this for at least two reasons. First, there is the need, already mentioned, to concentrate as carefully as possible upon a relatively precise problem or set of problems. And second, the acceptance of a utilitarian function for the legal system is, for the purposes of this study, as much a matter of convenience as commitment. That is to say, although the study is avowedly concerned with the relationship between various decision procedures and a utilitarian goal, this is so in part simply because some goal or function of the legal system must be presupposed if evaluation is not to occur in a contextual vacuum. To a considerable extent, the persuasiveness of many of the conclusions reached in connection with an evaluation of these procedures is independent of the particular function assumed to be desirable. Thus, although some of

5. See, e.g., 14 J. LEGAL ED. 523 (1962) ; 10 U.C.L.A.L. REv. 238, 239 (1962); 16 RUTGERS L. REv. 483, 487 (1962). It should be added that Wasserstrom's book received generally enthusiastic reviews, of which one of the most valuable is that of H. L. A. Hart, 14 STAN. L. REv. 919 (1962). 
the arguments clearly stand or fall with the acceptance or rejection of a legal utilitarianism, others are logically independent of it. ${ }^{\circ}$

Wasserstrom does not seem to countenance the possibility that a legal system may have no "goal or function" of the sort which can serve the office of the utilitarian principle in his model. ${ }^{7} \mathrm{He}$ speaks as if the only debatable assumption he makes is that the function of law in our society is or ought to be "utilitarian," and he believes that the persuasiveness of the major conclusions he reaches is independent of that assumption. Perhaps so, but it is not independent of the tacit, more general assumption of some identifiable overriding "function" of our law, for the two-level procedure requires the use of some such function at the initial, or rule-testing, level.

Is it plausible to assume that each legal system, including our own, has or ought to have some such "function"? We must have a better idea of what we are being asked to assume than the quoted paragraph in itself provides. We might without reflection think that we are being invited to assume no more than that law ought to be purposeful, that is, that laws should be adopted by legislatures and decisions reached by courts not aimlessly, but rather with the expectation that some particular goal is to be advanced thereby. But this assumption (whatever we might think of it) falls far short of what Wasserstrom requires to make his two-level procedure work. For that procedure requires not merely agreement that each statute or a rule should have $a$ purpose but agreement that all statutes and rules should serve one ultimate purpose.

One other possible interpretation must be put aside. One might understand Wasserstrom to be saying, by his assumption that law should serve some "goal or function," no more than that judges should be subject to some ultimate standard or standards as to the rules they make and enforce, and that he is presently concerned not with what these ultimate standards are, but rather with the best procedure for assuring their proper application. If this were the burden of the assumption, we might have two caveats. First, we might wish to consider further whether there are any ultimate standards of judicial decision, other than the vacuous standard of justice, and whether, if there are any such, they are not so complex and so difficult of confident application as to make the statement of the initial level of the two-level procedure deceptively simple. Second, we might take linguistic exception to Wasserstrom's characterization of these ultimate standards, whatever they might be, as "goals" or "functions" of law, because this language suggests not standards in general, but one particular kind of standard, the forward-looking kind which directs the

6. WASSERSTRON at 10-11.

7. Unless he is denying that possibility when he says, "some goal or function must be presupposed ... if evaluation is not to occur in a contextual vacuum." This supposition is itself revealing, and confirms the conclusions as to interpretation of the principal assumption reached below. Why must evaluation of techniques of judicial decision proceed in terms of some ultimate goal to be reached by a legal system. There are other sorts of criteria, and the question of why these are inappropriate is the real question Wasserstrom should face. 
decision-maker to reach his decision in a manner calculated to advance a particular state of affairs considered desirable. It is thus inappropriate as a characterization neutral among all competing theories of what the ultimate standards of law should be.

But we need not pursue these caveats, for if we study the uses Wasserstrom makes of the concept of function we must conclude that this broad asstumption, that judges are subject to some ultimate standard or standards, will not serve his purposes either. For the two-level procedure is clearly trivial and superfluous unless a particular kind of ultimate standard, the forward-looking, state-ofaffairs-to-be-advanced kind, is assumed to be the appropriate test of judicial decision. The "utilitarian" standard Wasserstrom adopts "for convenience" is par excellence that kind of standard. But there are other kinds of standards which have been or may be advanced as the ultimate test of good law in general or proper judicial decision in particular. Consider the judge who believes the ultimate test of a judicial decision to be whether it represents the application of principles of fair play generally indorsed and publicized by the community. Of what use can the two-level procedure be to him? It tells him only to apply the standards he deems proper in reaching his decision and, of course, he is already prepared to do that. It gives him no help by directing him to test a rule of decision, as opposed to a particular decision, against that standard, because the standard he deems appropriate does not tempt, indeed would not permit, that distinction to be made in the first place. For him, the questions, "What is the appropriate rule to use in cases like the present case?" and "What decision would be the just or fair decision between the parties to the present case?" must receive the same answer because they are different forms of the same question. It would not matter which of the two forms he tackled, and the suggestion that he should tackle them both would be silly. The two-level procedure would be a confusing guide for such a judge to follow in reaching his decision, and a confusing structure for him to adopt in justifying it. For it calls for a calculation - testing a rule of decision for its power to promote some social situation - which would in fact be part of neither activity.

The only standards which might seem to require that these two questions be distinguished and this calculation be made, and therefore the only standards which might seem to benefit from enforcement through the two-level procedure, are those of the forward-looking, advancing-a-state-of-affairs kind, those, that is, which we would describe as pertaining to the "goal" or "function" of law. For these raise the possibility of situations in which one decision would advance the desired state of affairs if that decision had no repercussions on the future conduct of others, but, because it will have such repercussions, will actually retard it. In such situations, the author of the decision would do well to take into account such repercussions and this, in effect, is what the two-level theory directs him to do. The principal assumption Wasserstrom asks us to make, therefore, and which we must make if we are to accept the two-level 
theory as a general theory of decision, is that all law-making should be subject to some ultimate forward-looking standard.

One more clarification is necessary. At one point in the passage quoted above, Wasserstrom speaks of the "function or functions" of law. How many may we assume, and need they all be consistent? Is his tacit assumption satisfied if we add all the ambitions, or even all the creditable ambitions, of the several members of a community together, and regard the sum as indicating the "functions" of the legal system of that community? Clearly not, for these ambitions would be to some extent inconsistent, and before they could serve as the test of judicial decisions some hierarchy or compromise would be necessary, and would have to be made on the basis of some more basic function or consistent set of functions. It is such single function, or such a consistent set of functions as could logically be regarded as a single function, that we are called on to assume.

It seems perfectly clear that if the operation of our judicial system is subject to some ultimate standard, and if this fundamental standard is a forwardlooking standard, is a function in this sense, the two-level procedure is superior to both the procedure of precedent and the procedure of equity. But that is because it is tailored to forward-looking standards, and they are not. For the theories of precedent and equity, contrary in so many ways, are yet alike in that the appeal of each depends upon the claim that some standard which is not a forward-looking standard (such as the principle of fair play that rules must be announced before they are applied, or that it is unfair to surprise one who has relied upon established rules, on the one hand, or the principle that the party having the morally inferior claims should not be preferred in court, on the other hand) lies among the most fundamental standards to which judges ought to be subject.

The real question at issue between Wasserstrom and proponents of precedent or equity is not which procedure is best calculated to reach a state of affairs taken as desirable. It is whether the test of a judicial decision should be a calculation of this sort at all. But the answer to that question is precisely what Wasserstrom assumes.

These considerations help, I think, to display both the assumption Wasserstrom actually makes with respect to the "function" of law and its role and importance in his argument. We should return to the question which prompted them: Is this assumption plausible?

It is not obvious. What arguments could be made in its support? The most likely and important argument, at least so it seems to me, is this: In any community, and in particular in ours, some very general goal is so basic and so widely held that it can be said to be a goal to which the community as such is committed. Since a legal system should serve the community in which it operates, it should serve the "function" of advancing this goal, and judges should therefore decide cases using this "function" as their ultimate standard.

It is important to see that two claims are built into this argument, and that it may therefore be incorrect in two ways. First, it might be that in our - or 
any other particular - society there simply is no sufficient consensus on an overriding goal to say that any particular function of law forms part of the standards of the society as such. For it is not enough to establish such a standard to show that a goal - say, increasing over-all happiness - is held of valte by the community; it is necessary to show that it is held of overriding importance, so as to entail disregard of any other values insofar as they are inconsistent. Second, even assuming that a community has settled upon an overriding goal to be achieved by its law, that community might also have established a jurisprudential principle to the effect that its courts are not to look to that goal as a test of the rules of law they adopt but are to leave to other institutions of government the business of testing subordinate legal standards against such overriding function.

It is difficult to see how the first of these claims, that our society has fixed upon some overriding goal which is thus the proper function of its law to advance, should be tested. Presumably, however, such a claim is rebutted, with respect to any particular suggested goal, if we can imagine legislation which would not be acceptable to the community even if it were convinced that such goal would be advanced by that law. Suppose, for example, that an economist were to demonstrate, to everyone's satisfaction, that the enslavement of persons whose I.Q.'s fell below a given level would advance the "greatest happiness of the greatest number" and would thus be justified on a "utilitarian" standard of good law. We should nevertheless, I believe, be outraged by either congressional or judicial legislation to that effect. Such legislation would be prohibited by constitutional restraints in the United States. But these restraints are themselves evidence of, and are to a large extent composed of, social commitments which, at times at least, transcend general utility. The legislation would, moreover, be viewed as equally outrageous in the absence of those restraints (say, in England). The only suppositious overriding goal which would seem immune from such attack by counterinstance is the goal of the "just state," provided that by that we mean, vacuously, the state in which all law is as it should be. I may, of course, be wrong in this; it may be that a non-vacuous "function of law" can be suggested which would be proof against counterexample. But the "utility" function, at least in the traditional formulation Wasserstrom adopts, will clearly not do, and Wasserstrom would be unwise to assume without more that if it will not do, some other principle will. It may be that no single goal or consistent set of goals enjoys the status in our society which the goal of utility does in his model. Indeed it seems more plausible to assume that this is rather than is not the case.

But even if we suppose arguendo that our society does accept the utilitarian principle, or some other forward-looking standard, as an overricling test of desirable legislation, it in no way follows that our courts should apply such a standard as an ultimate test of their work. The failure of that implication is reflected, I think, in current jurisprudential attitudes. Consider Wasserstrom's key example of the two-level procedure in operation: A poor widow defaults 
in servicing a loan secured by her home, and the already rich banker secks foreclosure. 8 The "equitable" theory he rejects would suggest, he believes, decision for the widow, on the ground that the needs and interests of the parties at bar are best served thus. But that result will discourage bankers from lending to other widows, the very people who need loans most, and so will hurt the class it was intended to protect. Granted the desirability of mortgages as a credit institution, Wasserstrom concludes, the rule that mortgages should be enforced against poor widows is a good one, and should be enforced.

But suppose the judge before whom this particular case comes does not grant the desirability of mortgages as a credit institution? Suppose, after the most thorough study of whatever economic or other evidence can be produced, he concludes that the needs and interests of society would best be served by eliminating mortgages, like wagers, as enforceable arrangements of promise? According to the two-level procedure, it would be the duty of this judge not to enforce the widow's mortgage, or any other mortgage for that matter. But a judge who refused to enforce mortgages on the ground that they were of negative utility would be regarded by the profession and the public as having decided wrongly, not simply because (or if) he was wrong in his assessment of utilities but because he was wrong to regard the question of the value of mortgages in general as open for him to pass upon. We should not say that his fault consisted merely in bad economics (for then we should have to admit that, once having made the mistake, he acted properly in deciding as he did) but in bad jurisprudence, in a mistaken notion of the sort of questions he is entitled to and obliged to answer. We might admit that if our legislators came to the same conclusion, they ought to legislate prohibiting mortgages, that if any one legislator came to that conclusion, it would be his duty to press for and vote for such legislation and still deny that a judge of that opinion should so legislate judicially. A particular standard may be accepted socially as one proper test of the value of legislation, yet not so accepted as a test of propriety in judicial law-making. To suppose that the standard used for one purpose must be carried over to the second is to assume that law-making institutions must necessarily be fungible.

I must be careful not to be taken as suggesting that judges are never entitled or obliged to modify existing rules of law. Of course they sometimes are, and one can learn a good deal about our jurisprudence by reflecting on the occasions on which they are. Suppose a court creates an exception to the general rule that mortgages should be enforced, by holding a mortgage unenforceable when it contains certain especially stringent provisions. That decision might be considered right by the profession and the interested public, for example, if the terms in question were such as would be considered unconscionable by poptlar standards of fair business practice, if the legislature had recently enacted a comprehensive statute defining and regulating a similar credit device, like conditional sales agreements, which declared such terms. invalid in those agree-

8. Id. at $141-44$. 
ments, and if there were prior cases in which the court had in other ways shown itself uncommitted to a policy of complete freedom of contract in the mortgage area.

The decision would not necessarily be regarded as wrong in these circumstances even though a critic were able to demonstrate that these various public, legislative, and judicial judgments on which the court had relief were in fact inconsistent with or obnoxious to a goal of "maximizing satisfactions" within the society. In other words such limited public standards as these judgments represent are not generally regarded as intermediate steps between rules of law and an ultimate utilitarian goal (or any other ultimate goal) of law. Such standards do not become good reasons for a particular judicial decision only if they themselves pass the test imposed by such an ultimate function. Their acceptability as reasons for a judicial decision seems under present practice at least to depend on whether they can fairly be said to represent community standards, rather than whether on some assumed overriding principle, they ought to. And it is worth noticing that these limited standards which may be dispositive of particular cases will include standards which are not forward-looking standards.

(It might be objected here that if we do expect our legislature to make decisions on the basis of some overriding goal like utility, then it is perverse of us not to expect our courts, if they "make law" at all, to do so on the basis of the same standard, and that we should therefore change our expectations. But wherein does the perversity lie? Why should society change its critical standards with respect to courts to accommodate its critical standards with respect to legislatures? Its standards of judicial decision may reflect profoundly valued principles about the circumstances in which members of the community should be punished or held responsible for damage suffered by others, principles which are much less relevant to the legislative process than to the judicial. But even if society's legislative standards must be taken, for some reason, to be of superior importance to its judicial standards, it does not follow that the two sets of standards are inconsistent. Indeed, it might be that the legal process should itself be viewed as operating on two levels, like the two levels on which Wasserstrom urges that courts should operate. Perhaps an assumed, overriding goal like utility is best advanced if courts make rules on the basis of present community standards, principles, and policies [like those referred to above with respect to mortgage terms] without reference to their utility, and legislatures or other institutions test the utility of such principles and policies, substituting others if they find the incumbents wanting. I indicated earlier that I regard the assumption of a fundamental social goal as chimerical, even as a legislative standard. But it is odd that Wasserstrom, who apparently does not, never considers a more inclusive two-level procedure as a possible technique for insuring the long-distance progress of the entire legal system toward that goal.)

It might be helpful to attempt a summary. Wasserstrom makes the tacit assumption, which is necessary to give his two-level procedure significance, 
that the legal system of a society should serve some general overriding function, like that of utility. On analysis this assumption is seen to involve more than that law-making should be purposeful, or that law-making should be subject to some sorts of standards. It assumes that law-making should be subject to one kind of standard, the forward-looking standard of some ultimate state of affairs to be reached, and that this standard should apply to the law made by courts as well as the law made by legislatures. So understood, the assumption seems less obvious and more crucial than it might at first. For it assumes what is actually the principal issue at stake among advocates of the two-level and other possible decision procedures, and in this sense the remainder of the book is anticlimax. It becomes necessary, therefore, to focus our attention on this assumption, to determine whether it is acceptable. It might be thought that it is required or implied by some fundamental political or jurisprudential principles at large in our community to which law is thus committed. But on reflection the contrary seems to be true. It may, of course, be that for some reason our present jurisprudential principles should be abandoned and those represented by Wasserstrom's assumption substituted. But no compelling reasons why this should be done come to mind, nor does Wasserstrom supply any.

Another of Wasserstrom's basic assumptions, another explicit feature of his model system, should be mentioned because it is so intimately connected with that we have been exploring. He assumes that his model contains no legislative rules of law. If our society had no legislatures, the possible distinctions we have been discussing between the standards our society holds with respect to judicial law-making and legislative law-making quite obviously could not exist, the courts would have to do much of what the legislatures now do, and so our present legislative standards might well become judicial standards. The claim that the courts ought to test their rule-making against some ultimate social goal would be at least more persuasive as to a society such as Wasserstrom assumes than as to ours.

But that is precisely the point. Wasserstrom supposes the analysis of his legislature-less model to be pertinent to our legal process. The most revealing thing about the stipulation is his apparent opinion of its consequences:

The whole of this investigation assumes that no legislative rules of law are present within the legal system. That is, all the procedures analyzed are deemed to be devoid of statutes. The only kinds of legal rules that are here considered to be available to a court are those rules which can be or which have been made by the judiciary. The reason for this restriction can be briefly indicated. As soon as statutory rules of law are admitted into the decision procedures, intricate issues of political theory become relevant. It might be argued, for example, that a court ought always to apply the rules of law laid down by the legislature simply because this is the function of the judiciary in a tripartite form of govrenment. Proper analysis of this argument might involve considerations of the desirability of various forms of government and of the proper relations between organs of government. These are surely issues that merit careful study, but they do not really serve the purposes of this inquiry.

9. Id. at 8 . 
He believes that the restriction affects the pertinence of his argument to the work of our courts only by eliminating some arguments as to how our courts ought to decide one class of cases (cases in which rules adopted by the legislature purport to determine the result) and not otherwise. He eliminates the legislature as a matter of convenience only, to narrow the inquiry by ignoring such cases. His confidence that this is the only result of his stipulation dramatically illustrates his assumption of institutional fungibility: the supposition that if and to the extent that courts and legislatures both "make law" the same standards are or ought to be applicable to them in that capacity.

This is a very widespread supposition, and Wasserstrom's elimination of the legislature from his model "for convenience" is but its extreme extension. Those who hold it may disagree among themselves about the extent to which coirts should make law; but that disagreement assumes and is indeed abetted by agreement that permitting courts to make law is permitting them within some area however circumscribed to make decisions in the same manner, that is subject to the same and only the same standards, as is a legislature. Such agreement underlies most argument that courts should or should not have "discretion," and the commonplace description of courts as legislating "interstitially," by "delegation" from the legislature, and as "filling in" detail between the legislature's broad brush strokes. The controlling image of the supposition is that of the superior and the inferior decision-maker - the general and the lieutenant - who differ in the fact that the latter owes obedience to the former, and thus in the scope of the power of each to initiate and to make fresh choices on his own but not in the manner in which each is expected to reach and justify such choices as have in fact been left for him to make. If this image fairly represents the institutional arrangements of our legal system, then Wasserstrom's stipulation involves only the limited curtailment of his inquiry which he recognizes. But if it does not, then the analysis of his model legal system threatens to become, as a guide to the proper practice of courts in our more complex community, simply irrelevant. That it does not is suggested, I think, by the mortgage example put above. A legislature would be justified, under present community attitudes and expectations, in voting to outlaw mortgages as commercial devices in circumstances in which a judge would not be justified in deciding to outlaw them, and this distinction does not depend upon showing that the legislature has made a judgment that mortgages are to be enforced which the courts are obliged to respect, or that the legislature has somehow acted to remove the whole question of the validity of mortgages from the scope of the courts' concern.

One further exercise may be helpful in clarifying the point that Wasserstrom's analysis is designed for, and only fits comfortably, institutions which are unlike our courts in critical respects. Consider how apt the analysis Wasserstrom gives of the judicial process would be if it were applied to some office whose holder is charged with applying an overriding, forward-looking standard to his decisions: the corporation president, for example. The president must set policies which in many instances take the form of rules - the prod- 
ucts his company will manufacture, the prices it will charge, the areas in which it will distribute. He must also, from time to time, pass judgment on how faithfully his subordinates have carried out his instructions, most often for the purpose of censuring those who have disobeyed him. It is plausible to assume that all of his decisions should serve (so far as the law permits) a particular function - the function of increasing his corporation's profits; the wisdom or foolishness of these decisions must be determined by asking how well they serve this function.

The president's policy decisions are limited by decisions of his institutional superior, the board of directors of the corporation. Insofar as the board decides questions of price, he may not. But to the extent to which the board delegates this question to the president, he must make his decisions in accordance with the same test - profits - as the board would have used had it made the decisions. Thus the question faced by the board in deciding whether to make pricing decisions itself, or to delegate them to a president (who in turn may delegate them further) is a question of who is most competent to apply the agreed test, not of which test will be applied. It might therefore be prudent, in studying the test which the president should use of his decisions, to adopt a model simplified in that it assumes a corporation without a board.

Suppose that the president, having fixed the price of a major item, finds that an energetic salesman has sold out the entire line at a higher price. Shall the salesman be censured or praised? One adviser counsels that he be praised on the grounds that his act, after all, increased corporate profits. Another warns that if he is praised, others will be encouraged to disobey future presidential price decisions with an assumed long-term injury to corporate profits. The second adviser might admit that the particular sale at a higher price has helped the corporation, and that if the worth of the act could be judged apart from the effect of the judgment on the future enforceability of other price decisions, it should be praised. But he denies that it can be so judged and so urges that it be condemned. The arguments which Wasserstrom advances for his two-level procedure over the "equitable" procedure would seem pertinent to this issue, and decisive in favor of the second adviser. We might generalize, and instruct the president that he ought always to adopt a two-level approach to the rules he establishes for his organization. When deciding upon his rules, he ought to find the best rules; when applying a rule, he ought to apply it even though its application might censure an act which, considered in isolation, was better for the corporation than the act demanded by the rule would have been. We might excuse our executive if he felt neither troubled nor enlightened by these general instructions. They would nevertheless be appropriate as general instructions, for the reason that, and insofar as, the president's task is to apply an exclusive, forward-looking standard to his decisions. ${ }^{10}$

10. There remains, of course, the question, not here discussed, of whether the two-level procedure, even if appropriate, is feasible. The answer depends, to a large extent, on the "function" selected. No court, it is submitted, could successfully apply the "utilitarian" function in the form offered by Wasserstrom as a sample. 